\title{
Managing Lifetime Wastivity
}

\author{
Prof. Sushil ${ }^{1}$ (D)
}

Received: 6 June 2018/ Accepted: 19 June 2018/Published online: 9 July 2018

(C) Global Institute of Flexible Systems Management 2018

\begin{abstract}
Wastivity is a wholesome measure of performance of any system. It considers the waste generated during the working of any system concerning the input provided to the system. This article deliberates on the concept of 'lifetime wastivity' of any system incorporating the waste of all types of resources such as material, energy, manpower, capital, and time. It first considers the context of electrical power systems, based on fossil fuels such as coal. The lifetime wastivity in the electricity sector is of very high order incorporating energy wastivity of all the processes in the life cycle, auxiliary energy wastivity, and different types of pollution-related wastivity at all stages. The paper takes another example from services sector such as hospitality industry. There is a need to put in place wastivity accounting and audit systems to portray the pattern of wastivity of different resources overtime to minimize lifetime wastivity. As an editorial, it also gives a brief of all the papers scheduled in this issue.
\end{abstract}

Keywords Lifetime wastivity - Waste management . Wastivity

Wastivity is considered as a wholesome measure of performance of any system. It considers the waste generated during the working of any system concerning the input provided to the system. Waste is a normative measure regarding any unnecessary input to the system and any

Prof. Sushil

sushil@dms.iitd.ac.in; profsushil@gmail.com

1 Department of Management Studies, Indian Institute of Technology Delhi, Vishwakarma Bhawan, Shaheed Jeet Singh Marg, New Delhi 110016, India undesirable output from the system. For example, Vrat (2014) considered material wastivity as a ratio of the material wasted and total material consumed in a period. In the context of lean manufacturing, any non-value adding activity is considered as waste. The relevance of wastivity goes high in the context of fast depleting resources and growing environmental pollution. This article deliberates on the concept of 'lifetime wastivity' of any system incorporating the waste of all types of resources such as material, energy, manpower, capital, and time. The lifetime of any product is considered from its identification to development, manufacturing, marketing, use, and ultimate disposal. At all the stages in the life cycle of a product or service, the overall system has to be managed to perform at lowest lifetime wastivity.

For example, let us consider the context of electrical power systems, based on fossil fuels such as coal. The different stages are mining of coal, transportation of coal, conversion of chemical energy into electricity generation, transmission and distribution of electricity, utilization of electricity for end use in domestic and commercial usage and allied production of related equipment, and waste created at each stage. In case of mining, the waste is broadly regarding wastewater, dust, coal powder, and health hazards. The wastivity is accounted regarding coal wasted in mining concerning the total potential coal in the mine on the one hand and consumption of auxiliary energy by various mining equipments on the other hand. It also adds a lot of environmental pollution. Next lies the transportation of coal from the mine to the power plants, which may have at least $10 \%$ of wastivity of coal directly and additional wastivity of transportation system energy. The next process is the generation of power in the coal-fired power plants, which can have wastivity to the tune of $40-50 \%$, depending upon the efficiency of the boilers and 
power factor of the operation of the plant. It may further add wastivity due to the consumption of auxiliary power in a lot of equipment used in the operation of the plant. In addition to the wastage of energy in the generation of electric power, there is a major waste of fly ash, which needs to be handled, transported, reused, and ultimately disposed of in a safe manner having wastivity both regarding energy wasted in these processes and environmental pollution created. The next process in the electricity sector is transmission and distribution (T\&D). The T\&D losses or wastivity could be to the tune of $10-30 \%$ in different countries, the highest losses being in the case of India. This process also has losses due to the consumption of auxiliary power in T\&D. Finally, the electricity is put to use for commercial, industrial, public services, and residential use. The wastivity of electricity in final use depends upon the efficiency of various types of end-use equipment, wastage due to careless and neglect, and non-use of smart technologies. The wastage of electricity is also accompanied by different types of pollution. All these equipments have a working life and need to be finally disposed of which would further consume energy and may also create pollution of different kinds. Thus, the lifetime wastivity in the electricity sector is of very high order incorporating energy wastivity of all processes in the life cycle, auxiliary energy wastivity, and different types of pollution-related wastivity at all stages.

We can take another example from services sector such as hospitality industry. ITC, in India, has Welcome Group of hotels which is effectively managing different types of waste in this industry. Some important types of waste in the hotel industry are energy waste, wastewater, food waste, and capacity waste. The movement toward sustainability in this sector is related to zero energy buildings, zero wastewater, and zero waste to be finally disposed. The aim of zero energy building can be attained both by eliminating wasteful consumption of electricity in lighting, heating, and air-conditioning and by generating electricity from renewable resources. The wastage in lighting in corridors can be minimized with sensor-controlled lighting in corridors to minimize unnecessary lighting of corridors when there is no movement of anyone along the corridor. The heating of water and air-conditioning of rooms can be controlled based on occupancy. The wastewater from the bathrooms/toilets can be minimized by controlling the leakage and recycling the used water by installing treatment plants. The food waste and other types of waste need to be segregated and recycled to generate compost/electricity/gas for use in the hotel. A major waste in hotels is that of unused capacity that can be reduced by proper planning, dynamic pricing, and scheduling using IT support systems. Similarly, the linked waste is of support manpower that also needs to be minimized linked with capacity utilization. There are many other associated resources whose wastivity needs to be reduced for which sustainability goals should be specified and proper monitoring and control mechanisms to be implemented. There is a need to put in place wastivity accounting and audit systems to portray the pattern of wastivity of different resources overtime to minimize lifetime wastivity. Such waste accounting systems will provide the assessment of waste of different resources with one unit, i.e., a room in a hotel (both occupied and unoccupied) taking into consideration the whole life cycle.

Apart from the core theme of this editorial article, a brief about all the papers included in this issue is also provided. The first paper (Singh et al. 2018) deals with the context of electronics manufacturing which has to deliver goods and services with the latest technology and in a short span of time. The industrial competitiveness of the electronics manufacturing industries has certain determinants that have been analyzed using total interpretive structural modeling (TISM) and analytic hierarchy process (AHP) to rank these determinants. The second paper (Chowdhury and Jangle 2018) uses critical systems thinking to build a conceptual framework for enhancing community engagement in the microinsurance scheme. It discusses learning from an on-ground scheme in India and introduces select systems thinking tools for better conceptualization. The third paper (Zahraee et al. 2018) takes the case of the automotive industry in Iran. It evaluates the role of suppliers in green initiatives and identifies the drivers of supplier participation as society, environmental regulations, customer investment, and customer requirements. The fourth paper (Khorasani 2018) develops an optimization model for flexible and agile supply chain under uncertainty. It considers multiple objectives such as minimizing production line stoppage, supplier complaints, and defective parts and maximizing on-time delivery. These objectives in a way reduce the waste and total cost of supplying parts. The fifth paper (Rathore et al. 2018) takes the case of a smartphone to analyze social media data input for new product development. It extracted and analyzed Twitter data and carried out content analysis and network analysis. These papers included in this issue directly or indirectly address the concerns relating waste in different domains such as electronics manufacturing, microinsurance, green initiatives and optimization of supply chain, and product design.

The illustrative examples are taken in this short article, and the summary of papers included in this issue addresses different aspects related to waste management and lifetime wastivity. The management of waste of different resources at different stages in the life cycle of any product or service contributes to minimizing lifetime wastivity. The waste of any product or service in end use does not only increase the 
wastivity at that stage but should be accounted with accompanied wastivity at all the stages in the life cycle. There is a need to establish measures and models for assessing lifetime wastivity of different products and services to get a holistic picture of all accompanied wastes with the end-use wastage of resources.

\section{References}

Chowdhury, R., \& Jangle, N. (2018). Critical systems thinking towards enhancing community engagement in micro-insurance. Global Journal of Flexible Systems Management. https://doi.org/10.1007/s40171-018-0188-6.

Khorasani, S. T. (2018). A robust optimization model for supply chain in agile and flexible mode based on variables of uncertainty.
Global Journal of Flexible Systems Management. https://doi. org/10.1007/s40171-018-0191-y.

Rathore, A. K., Das, S., \& Ilavarasan, P. V. (2018). Social media data inputs in product design: Case of a smartphone. Global Journal of Flexible Systems Management. https://doi.org/ 10.1007/s40171-018-0187-7.

Singh, M. K., Kumar, H., Gupta, M. P., \& Madaan, J. (2018). Analyzing the determinants affecting the industrial competitiveness of electronics manufacturing in India by using TISM and AHP. Global Journal of Flexible Systems Management. https://doi.org/10.1007/s40171-018-0182-z.

Vrat, P. (2014). Materials, management: An integrated systems approach. New Delhi: Springer.

Zahraee, S. M., Mamizadeh, F., \& Vafaei, S. A. (2018). Greening assessment of suppliers in automotive supply chain: An empirical survey of the automotive industry in Iran. Global Journal of Flexible Systems Management. https://doi.org/10.1007/ s40171-018-0189-5. 